\title{
THE DIAGNOSTIC VALUE OF PLEURAL BIOPSY IN BRONCHOPULMONARY CARCINOMA
}

\author{
BY \\ WALTER PAGEL AND SUSAN GOLDFARB \\ From the Department of Pathology, Clare Hall Hospital, Herts
}

(RECEIVED FOR PUBLICATION DECEMBER 21, 1959)

\begin{abstract}
The diagnosis of bronchopulmonary carcinoma was either corroborated or arrived at in 13 out of a total of 26 cases by pleural biopsy. Taken as a whole, pleural biopsy is inferior to repeated examination of the pleural exudate for neoplastic cells. In individual observations, however, the former can be found positive at a time when neither the pleural fluid nor any other material provide a diagnostic clue.

In an instance of primary pleural growth (mesothelioma) its nature was recognizable in the pleural biopsy material.

Pleural biopsy can correctly lead to the diagnostic exclusion of growth in favour of tuberculosis.

Pleural biopsy can be suggestive of the rheumatic aetiology of changes.

A pleural biopsy positive for carcinoma can be obtained on both sides.

All stages, from early submesothelial deposition of individual neoplastic cells to the dense infiltration of the subserous connective and fat tissue, were observed.
\end{abstract}

The diagnostic usefulness of pleural needle biopsies has been pointed out on several occasions (Hill, Hensler, and Breckler, 1958; Mestitz, Purves, and Pollard, 1958 ; Leggat, 1959 ; Karlish, $1959 \mathrm{a}, \mathrm{b})$. The results were particularly impressive in the large series (228 biopsies) presented by Mestitz et al. (1958).

However, no unanimity has been reached as to the real usefulness of the method and this seems to be the reason why it has not yet been adopted generally and routinely. Informative individual case reports are therefore still called for, and those given in the present paper from a comparatively small series largely confirm the favourable view arrived at before. However, while helpful in certain instances, the method does not appear to be indispensable and not infrequently fails at a time when other diagnostic methods, such as the examination of pleural fluid and bronchial biopsy, have led to the desired result.

\section{The Present Series}

The series comprises a total of 26 cases in which pleural biopsy was performed uniformly with the Adams (or Harefield) needle on one or several occasions for the diagnosis of bronchopulmonary carcinoma. It was positive in 13 cases and negative in 13 .
In all 13 positive cases the diagnosis was confirmed: in six by bronchial biopsy, in four by suggestive bronchoscopic findings, and in six by examination of the pleural fluid and/or sputum for neoplastic cells. Of the 13 negative pleural biopsies, seven were in cases of carcinoma.

It should be expected that a positive pleural biopsy implies the presence of neoplastic cells in the pleural fluid, and indeed the longer and more often this is searched the higher will be the yield of neoplastic cells. However, the pleural fluid can be found devoid of neoplastic cells at a time when the pleural biopsy does reveal carcinoma. This was found in two cases of the present series.

Against this there were three cases in which the reverse was seen, namely, neoplastic cells in the pleural fluid with a negative pleural biopsy. The latter event should be more common in view of the proximity of many lung tumours to the visceral pleural lymphatics. In our small series pleural biopsy was thus indicative of bronchopulmonary carcinoma in about half the cases and failed to do so in roughly one-fourth. It therefore compares unfavourably with examination of the pleural exudate which failed only in one-fifth of the cases (in 12 out of 67 cases) examined at Clare Hall Hospital in 1957-59. 


\section{Case Reports}

Of the individual cases the following are noteworthy:

(1) A man, aged 56 years, with one month's history of pain in the chest, cough, and dyspnoea, presented with a right pleural effusion that was aspirated several times. Bronchoscopy showed stenosis of the right upper lobe bronchus, but the bronchial biopsy was negative. A subsequent pleural biopsy was positive.

In this instance the positive pleural biopsy formed the only pathological evidence of carcinoma. On its strength no further investigations were made, as the radiological extent of the growth and the general condition of the patient rendered it inoperable.

(2) In a man, aged 62 years, with four months' history of cough, sputum, and dyspnoea, a left pleural effusion was found on $x$-ray examination. This was aspirated several times. On bronchoscopy narrowing of the left stem bronchus was found. Both the bronchial biopsy and pleural fluid were negative. Pleural biopsy was, however, positive.

Squamous-celled carcinoma was diagnosed from the pleural biopsy on two occasions at a time when no evidence was forthcoming from the bronchial biopsy and the pleural fluid. Bronchoscopically, however, a suggestive stenosis was seen.

(3) This patient, a man aged 67 , had a two years' history of hoarseness of the voice. He then developed gastric symptoms for which he was investigated. Radiographs showed a large mass in the right upper zone. Bronchoscopy showed a narrowing of the lower trachea and stenosis of the right main bronchus. Bronchial biopsy did not reveal any neoplastic changes. The pleural biopsy, however, contained units of squamous-celled carcinoma.

This case was almost a replica of the previous one. Carcinoma was found in the pleural biopsy, with a negative bronchial biopsy in spite of bronchoscopic findings suggestive of bronchial stenosis.

(4) In a man, aged 57 years, with six months' history of cough, dyspnoea, and haemoptysis, the chest radiograph showed multiple bilateral opacities. There was a small right pleural effusion. Oat-celled carcinoma was found in several pleural biopsies and in an enlarged right supraclavicular lymph node, but no neoplastic cells were seen in the sputum.

In this instance a positive pleural biopsy antedated any other positive findings by about one month.

(5) In a man, aged 59 years, with progressive dyspnoea for two years a left pleural effusion was diagnosed. Though numerous aspirations were performed, only later were neoplastic cells found in the fluid. No changes could be seen on bronchoscopy. The needle biopsy was, however, positive (Fig. 1). Later, following an aspiration, he developed a pneumothorax. Radiographs taken at that time showed deposits on the thoracic wall.

In this case a growth that was most probably pleural in origin was discovered by pleural biopsy. The naked-eye appearance was of multiple, patchy, intrapleural deposits of a white growth (Fig. 2). Involvement of lung tissue was not demonstrable, either by naked eye or by histological examination, nor could any intrabronchial deposit be detected in a narrow series of sections through the specimen.

Histologically the growth consisted of tubular pseudo-adenomatous units showing central clefts lined by low cuboidal cells with scanty mitoses (Fig. 3). The growth conformed in type with what has been described as pleural mesothelioma or primary pleural tumour (Eisenstadt, 1956 ; Smart and Hinson, 1957 ; Forse and Haug, 1958). Particular reference should be made to the cases collected by McCaughey (1958) and his Figs. 10 and 11. In the present instance neither papillary structures nor neoplastic pleomorphic spindlecelled stroma, as often seen in these tumours, could be found.

Bronchoscopy and bronchial biopsy had been negative, but neoplastic cells were observed in the pleural fluid, though only after the diagnosis had been made from the pleural biopsy.

(6) In a man, aged 67 years, a pleural effusion containing neoplastic cells (Fig. 4) developed six months after a negative chest radiograph. Bronchoscopy showed narrowing of the left stem bronchus. A bronchial biopsy, however, was negative, whereas a pleural biopsy showed carcinoma (Fig. 5).

A case of oat-celled carcinoma of the bronchus proved by pleural biopsy on two occasions, on which neither the bronchial biopsy nor the sputum provided any evidence. On the other hand, such evidence was forthcoming from the pleural fluid.

(7) In a man, aged 68 years, with a history of chronic bronchitis and recent haemoptysis, the sputum was found to contain neoplastic cells (Fig. 6). After pleural effusion had developed, squamous-celled carcinoma was proved by pleural biopsy (Fig. 7), and a neoplastic mass blocking the left stem bronchus was seen bronchoscopically. Bronchial biopsy confirmed the pleural biopsy findings (Fig. 8).

This observation is reported in detail because of the scantiness of carcinomatous units in the pleural biopsy, calling for a careful and prolonged search, including cytological examination under oil immersion. In the present instance only one 


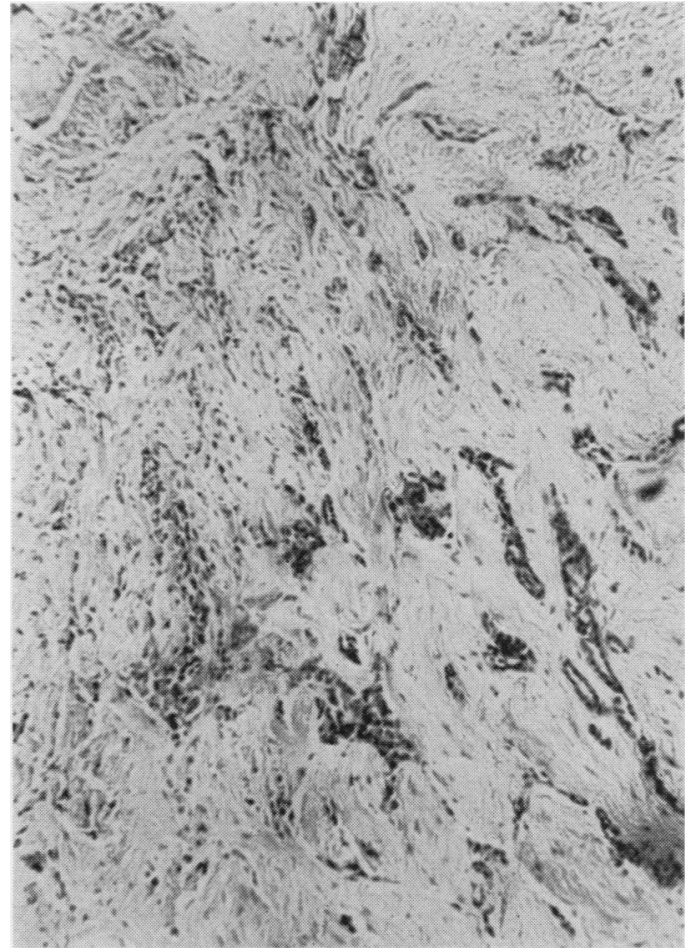

Fig. 1.-Case 5: Primary pleural growth (mesothelioma) in a man aged 59. Pleural biopsy $\times 100$ showed multiple clefts lined by uniformly low cuboidal "epithelia."

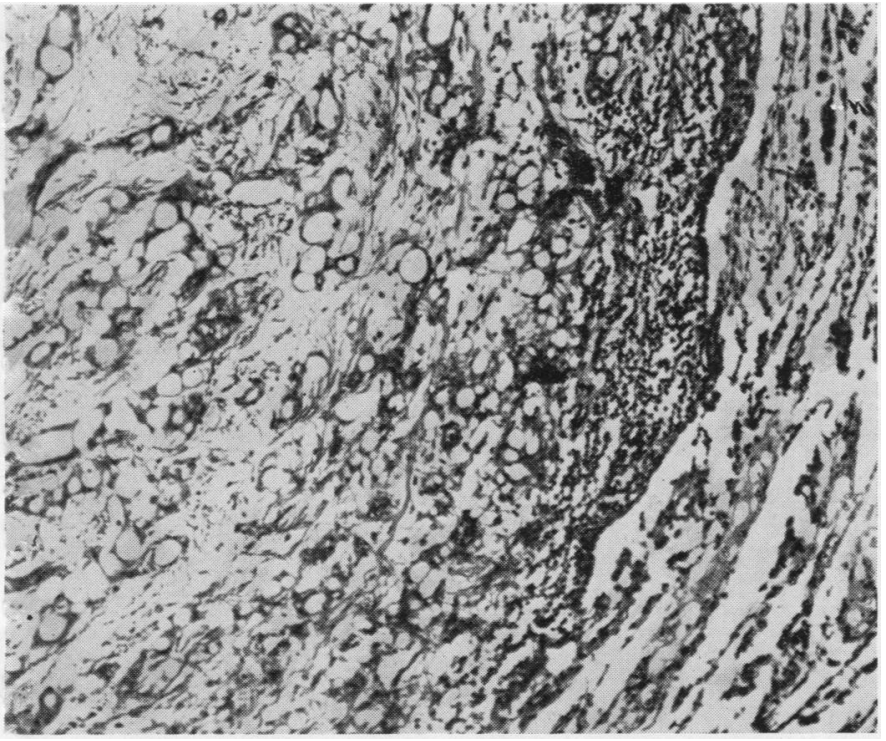

Fig. 3.-Case 5: Histological aspects of growth $\times 100$. The same pattern of clefts lined by "epithelium" as seen in Fig. 1, limited to visceral pleura, encroaching on but not infiltrating lung.

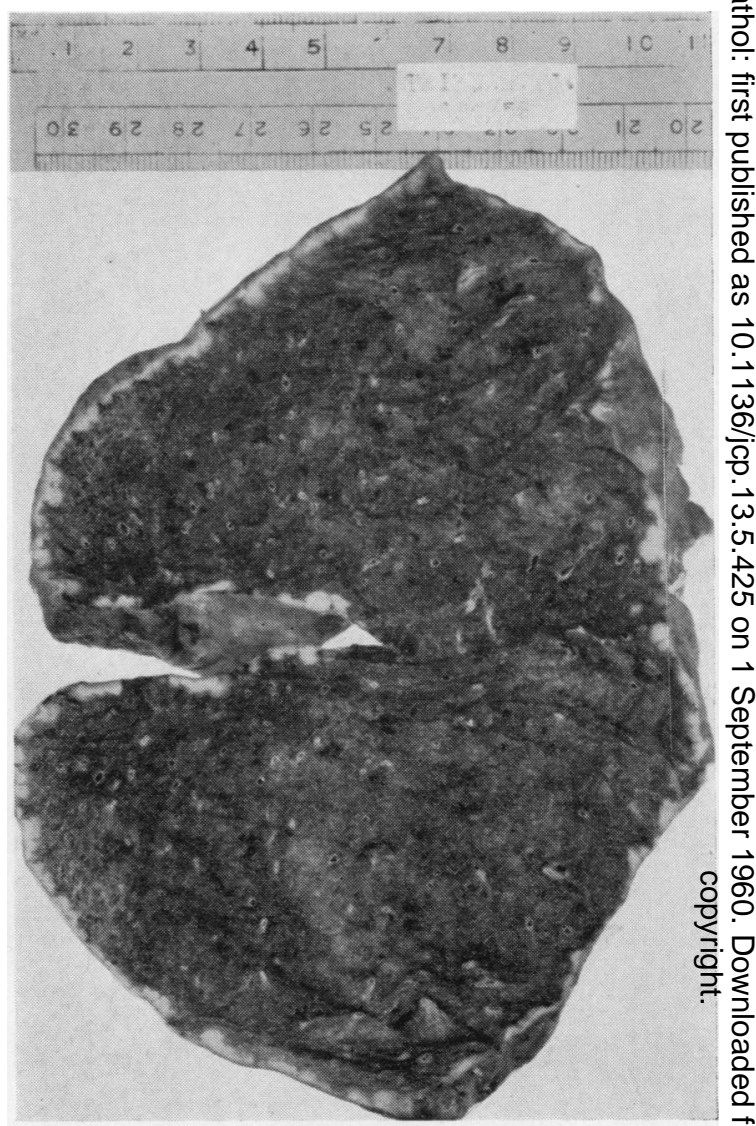

FIG. 2.-Case 5: Specimen showing multiple patchy deposits in the visceral pleura.

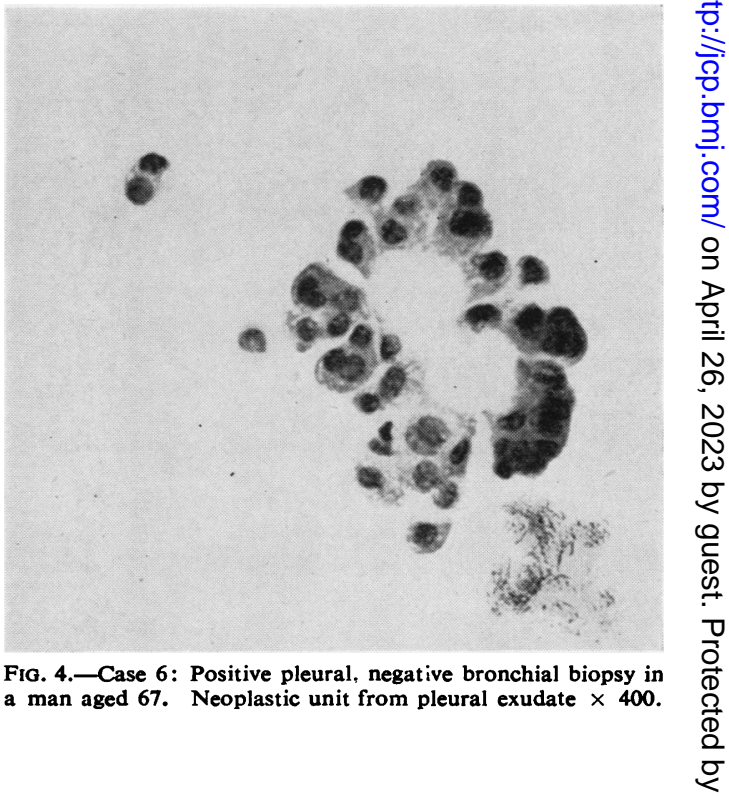






FIg. 5.-Case 6: Pleural biopsy $\times 100$. Dense infiltration of subserous fat tissue with oat-celled carcinoma.

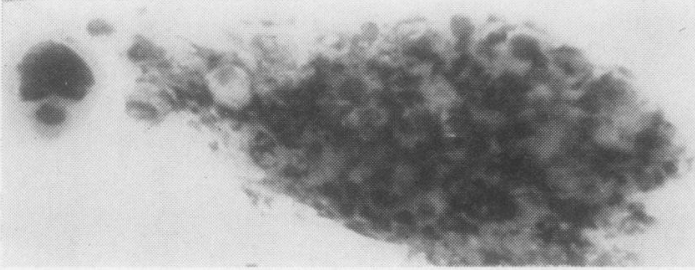

FIG. 6.-Case 7 illustrating scantiness of carcinoma cell units in pleural biopsy in a man aged 68 years. Neoplastic cells in sputum $\times 400$.

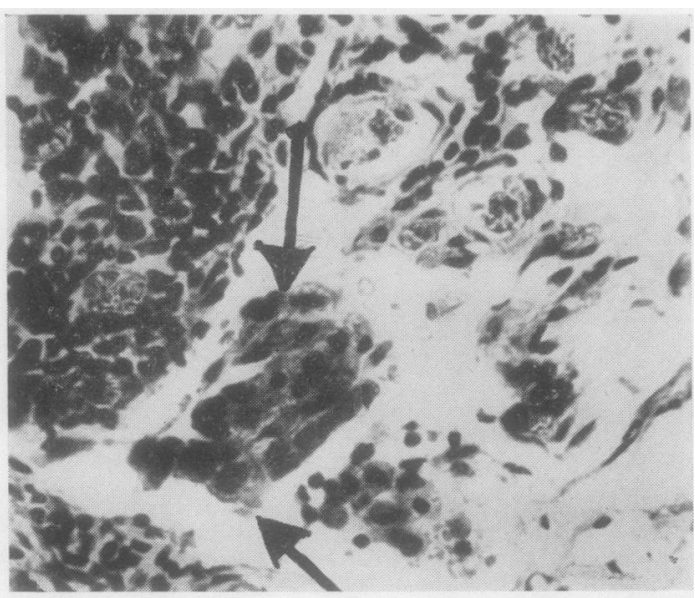

FIG. 7.-Case 7: Pleural biopsy $\times 400$ showing scanty units of carcinoma (arrows).

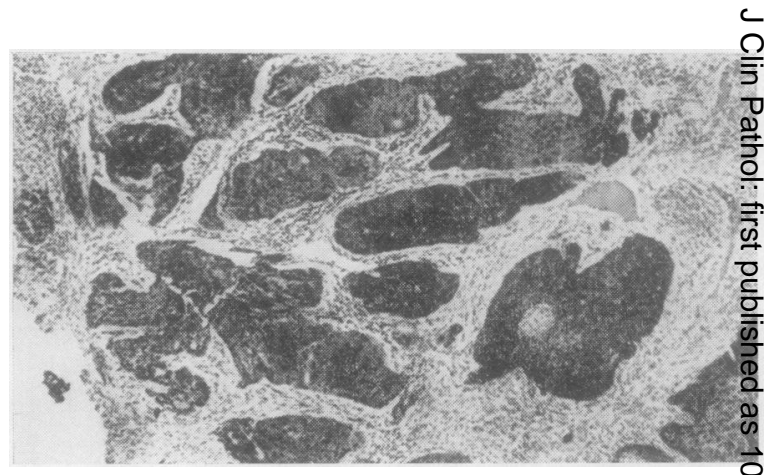

FIG. 8.-Case 7: Bronchial biopsy

40 showing squamous-celled carcinoma.

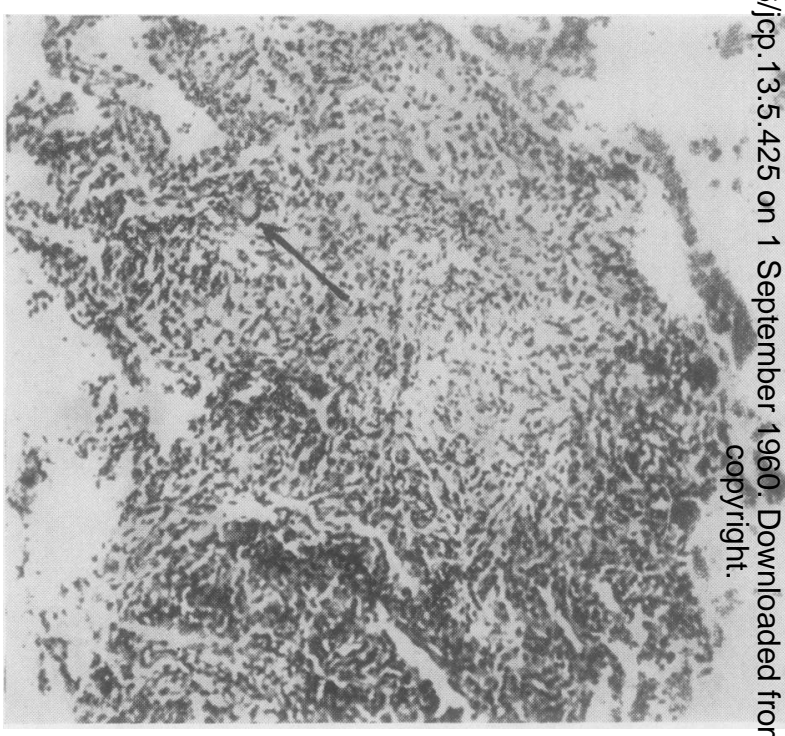

FIG. 9.-Case 8: Pleural biopsy with tuberculous changes in a woman aged 35. Pleural biopsy $\times 100$, "clearance" area. Peripherally a g鸟t cell (arrowed) of the Langhans type.

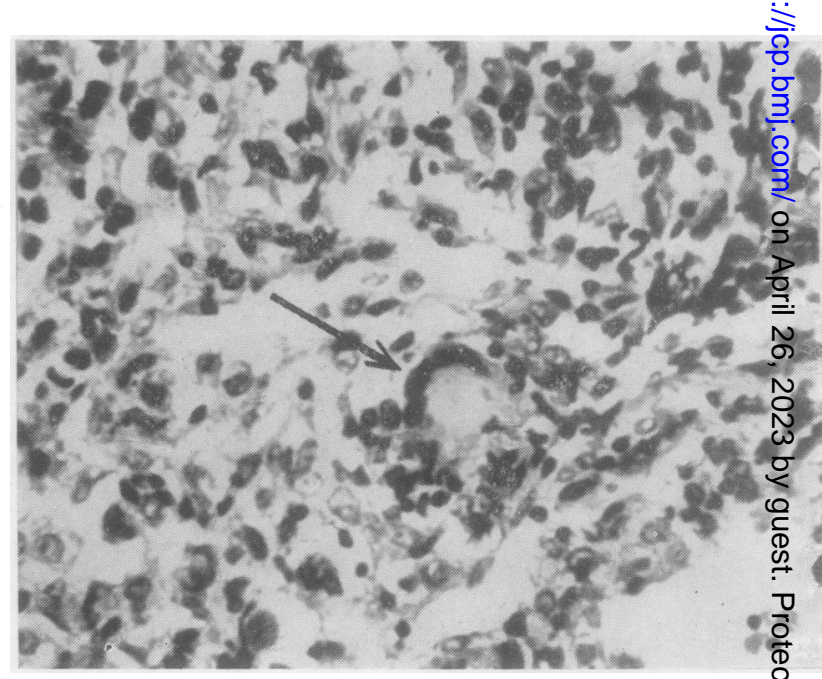

FIG. 10.-Case 8: The same as Fig. 9. Close-up of giant cell ( $\times 4$ 4 
of a mass in the lung was correctly suggested by pleural biopsy. The patient was a woman, aged 35 (Case 8), with a shadow suspicious of carcinoma in the right lower lobe, in spite of some history of tuberculosis treated with drugs. A pleural biopsy showed chronic inflammatory changes around an area of "clearance" and fibrosis with a solitary large giant cell of the Langhans type at the periphery (Figs. 9 and 10). The segment of the right lower lobe containing the suspicious change was then removed. It contained a tuberculoma (Fig. 11) with a broad peripheral zone of chronic collapse containing many non-caseating tuberculoid nodules that were rich in giant cells of the Langhans as well as the foreign body type. Both the naked-eye and histological changes closely resemble those observed in epituberculosis (Pagel, Simmonds, and Macdonald, 1953) and in this instance are due to chemotherapy.

The presence in a pleural biopsy of giant cells of the Langhans type in itself is no proof of tuberculosis. This is illustrated by a case in which pleural biopsy suggested a rheumatic aetiology. A man aged 53 years (Case 9), with recurrent multiple rheumatoid arthritis of 16 years' standing, developed, during a period of exacerbation, a unilateral pleural effusion. A pleural biopsy showed large mononuclear cells with a tendency to form giant cells of the Langhans type (Fig. 12). In a second pleural biopsy taken eight days later no giant cells of the Langhans type were seen, but there was distinct palisading of mononuclear cells with a tendency to form syncytia (Fig. 13). The changes were reminiscent of those seen in the cellular parts of rheumatic infiltrates. A suspicion of tuberculous aetiology (as suggested by the first pleural biopsy) could not be confirmed by clinical, radiological, or bacteriological evidence.

A pleural biopsy positive for carcinoma can be obtained on both sides. This was seen in a man aged 52 years (Case 10) with a shadow suspicious of growth in the right lower zone of the chest. The pleural exudate from both sides contained many neoplastic-looking cells. Pleural biopsies taken from both sides likewise showed units of carcinoma.

In the present series, in all positive cases a real infiltration of the pleural membrane by neoplastic cells or units was demonstrated compared with a merely superficial adhesion of neoplastic units deposited from the pleural fluid. The pictures observed fall into three categories: (a) Deepseated and extensive infiltration of the subserous fat tissue (Fig. 5) ; (b) patchy units lying in isolated lymph spaces, sometimes scanty and difficult to trace (Fig. 7) ; (c) superficial, but submesothelial infiltration, of isolated neoplastic cells or small groups mixed with blood or fibrin (Figs. 14,15 , and 16). The latter pictures illustrate the very early stages in the involvement of the pleural membrane in a marginal submesothelial lymph space. This is followed by larger units collecting in lymph spaces (Figs. 17 and 18). Both these stages were seen in two pleural biopsies taken simultaneously in a man aged 46 with squamouscelled carcinoma of the right main bronchus with pleural effusion (Case 11): the second stage was close to the growth itself where it was adherent to the parietal pleura, whereas the earlier changes of superficial submesothelial infiltration were found in a pleural strip remote from the former site.

A point of more general interest that emerges from the examination of pleural biopsies in bronchopulmonary carcinoma is the comparatively frequent presence of deposits in the parietal pleura. Perhaps this is less surprising in view of the pleural effusion that is present in most cases in which pleural biopsy is attempted, indicating an early involvement of the visceral pleura. Nevertheless the common occurrence of micro-deposits in the parietal membrane appears to be a subject worthy of systematic clinicopathological studies, with particular reference to the prognostic significance of such deposits.

The authors are indebted to Mr. R. Laird, Mr. T. W. Stephens, and Mr. G. C. W. James, senior surgeons, and to Dr. F. A. H. Simmonds, Dr. T. A. W. Edwards, and Dr. N. Macdonald, senior physicians, at Clare Hall Hospital, for case reports, encouragement, and help, and to Mrs. M. K. Barry for the photographic work.

\section{REFERENCES}

Eisenstadt, H. B. (1956). Dis. Chest, $30,549$.

Forse, M. A., and Haug, W. A. (1958). Amer. Rev. Tuberc., 78, 268. Hill. H. E., Hensler, N. M., and Breckler, I. A. (1958). Ibid., 78, 8. Karlish, A. J. (1959a). Brit. med. J., 2, 821.

- (1959b). Tubercle (Lond.), 40, 230, 396.

Leggat, P. O. (1959). Brit. med. J., 2, 478.

McCaughey, W. T. E. (1958). J. Path. Bact., 76, 517.

Mestitz P. Purves, M. J. and Pollard. A.C.(1958). Lancet, $2,1349$. Pagel, W.,'Simmonds, F. A. H., and Macdonald, N. (1953). Pulmonary Tuberculosis, 3rd ed. Oxford University Press, London. Smart, J., and Hinson, K. F. W. (1957). Brit. J. Tuberc. Dis. Chest, $51,319$. 